\title{
EDUCAÇÃO AMBIENTAL EM PRAÇA PÚBLICA: RELATO DE EXPERIÊNCIA COM OFICINAS PED AGÓGICAS
}

\section{Environment education in public squares a report about the experience with pedagogic workshops}

\author{
Luiz Fernando Rolim de Almeida ${ }^{1}$ \\ Luiz Roberto H ernandes Bicudo² \\ Gilberto Luiz de Azevedo Borges
}

\begin{abstract}
Resumo: O ficinas para professores do ensino fundamental foram organizadas com a finalidade de elaborar uma Proposta de Educação Ambiental em uma praça pública no centro histórico da cidade de Botucatu, no estado de São Paulo. Tais oficinas basearam-se em informações sobre o município e informações botânicas da Praça Rubião Júnior, em Botucatu, no âmbito da Educação Ambiental. 0 resultado foi uma proposta de Educação Ambiental para a praça com a participação efetiva dos professores, em que foi possível resgatar a história da cidade e seus aspectos sócio-econômicos. Foi também demarcada uma "trilha ecológica" nessa praça utilizando-se as plantas presentes no local, as quais foram previamente identificadas. 0 trabalho com os professores durante a oficina mostrou-se de fundamental importância para a formação desses profissionais e também estimulou seu interesse a respeito da história local. Essa abordagem, articulada com a diversidade cultural local, enriqueceu a proposta de E. A. e trouxe benefícios para a prática educativa.
\end{abstract}

Unitermos: Educação Ambiental, professores, praças públicas.

Abstract: Some workshops were carried out with H igh School teachers to make an Environmental Education Proposal for one square in the B otucatu citys historical center. The workshops were based on historical and botanical principles and were associated with the Environmental Education. As a result an ecological trail was designed through the plants, which had been previously identified. This project proved to be very important to the teachers in their professional growth. It boosted their interest in local history. This approach and the cultural diversity encountered enriched the proposal and brought benefits to teacher's practical teaching.

Key words: Environmental Education, teachers, public squares.

\section{Introdução}

A Educação Ambiental deve fornecer instrumentos para a sociedade ampliar discussões e ações concretas em relação às questões ambientais, sobretudo no âmbito das escolas de educação básica, de modo a ter uma população, pelo menosno futuro, consciente e educada para tais questões. Portanto, cabe à própria sociedade como um todo colocar em prática princípios educativos que permitam garantir a existência de um ambiente sadio para toda a humanidade de modo a conseguir uma conscientização realmente abrangente (AB'SABER, 1991). 0 papel da $E$. A. está em auxiliar a compreensão da dinâmica do ambiente e as relações dos elementos naturais e sociais. 0 entendimento dessas interações leva a uma reflexão sobre os processos históricos e sociais de transformação do meio natural e construído (REIGOTA, 1994).

\footnotetext{
${ }^{1}$ D epartamento de Botânica - U NESP - Botucatu.

${ }^{2}$ Idem.

${ }^{3}$ D epartamento de Educação - UN ESP - Botucatu. E-mail: bic@ibb.unesp.br.
} 
D essa maneira, princípios e práticas em Educação Ambiental podem favorecer a discussão e a solução dos problemas que afetam 0 ambiente. A população das metrópoles tem demonstrado crescente necessidade de aproximação com a natureza, sendo freqüente a visitação de áreas verdes. A utilização dos espaços verdes das cidades em conjunto com seu patrimônio histórico pode auxiliar seu despertar para a importância e complexidade da natureza, funcionando como uma extensão da escola.

0 patrimônio histórico e as áreas verdes que restam nos centros urbanos podem sucumbir aos impactos da atividade humana, sendo urgente a inserção de práticas de preservação do patrimônio cultural e biológico nos programas de Educação Ambiental. Praticada com esse objetivo, a E. A. em áreas urbanas pode facilitar o processo de conscientização da população indicando a necessidade da preservação dos centros históricos bem como a compreensão desses locais como exemplo vivo do ambiente historicamente construído pelo homem.

Pelos aspectos apontados, a problemática ambiental urbana constitui um tema bastante propício para salientar a demanda da população em conhecer e atuar nas áreas afetadas pelos crescentes impactos sócio-ambientais (J ACO BI, 1998). A atividade humana nos grandes centros urbanos representa a possibilidade de relacionar as questões conflitantes entre 0 ambiente natural e 0 ambiente construído. Entender essas relações pode trazer discussões sobre os problemas mais freqüentes para a população e otimizar os esforços do poder público para uma melhoria da qualidade de vida da mesma.

N esse sentido, é necessário o conhecimento articulado sobre a região onde vivem "homens-habitantes", "homens-produtores" e "homens integrados" em condicionantes sócioeconômicas. Para consolidar o corolário da E. A., torna-se imprescindível o livre trânsito nas escal as de social ização deste homem que começa na casa, atinge a rua e a praça, engloba o bairro, abrange a cidade, ultrapassa a fronteira das periferias dos grandes centros urbanos até integrar o mosaico dos espaços nacionais e planetários (AB 'SABER, 1991). Assim a compreensão das relações entre tempo-espaço e suas conjunturas possibilita conhecer as diferentes realidades sócio-ambientais existentes no ambiente urbano.

Assim, cada uma das praças públicas espal hadas pela área urbana tem a potencialidade de desenvolver programas de Educação Ambiental. N 0 entanto, a possibilidade de construção coletiva de ações vinculadas a essa temática implica em responder algumas questões fundamentais: Q ual a possibilidade efetiva do professor atuar no sentido dessa construção coletiva? Q ue formação dispõe para tal atividade pedagógica? Q ue aspectos da realidade utilizar no ensino-aprendizagem da temática ambiental?

Em síntese, as características do local e a possibilidade de um trabalho de E. A. com abordagem interdisciplinar permitem definir os objetivos para esse trabalho, visando à participação (envolvimento) dos professores de ensino fundamental, em especial aqueles das escolas mais próximas à Praça Rubião Júnior, em oficinas pedagógicas.

Dessa maneira, o presente estudo teve por objetivo organizar e executar oficinas pedagógicas com professores do ensino fundamental que possibilite o conhecimento e a execução de atividades de Educação Ambiental em locais com relevância histórica e cultural, além da ressaltar a importância ecológica do ambiente urbano.

\section{Temática ambiental e envolvimento dos professores na construção coletiva}

A E. A. nas escolas deve sensibilizar o professor e 0 aluno para que construam coletivamente 0 conhecimento por meio de estratégias pedagógicas de mudança de mentalidade. Assim, a E. A. pode propor um entendimento da ação humana sobre os diferentes ecossistemas, originados pelas diversas condicionantes sócio-econômicas da sociedade. N esse contexto, 
práticas de Educação Ambiental podem servir para estimular tais competências dos alunos, bem como proporcionar ao professor uma preparação e a aplicação dos conhecimentos às temáticas relacionadas com o cotidiano.

Segundo LiBÂNEO (1994), o papel do professor no processo educativo deve ser o de buscar os instrumentos pedagógicos que possibilitem uma prática eficaz e inovadora, sendo 0 processo de ensino uma atividade conjunta de professores e alunos, organizado sob a direção do professor, com a finalidade de promover as condições e meios pel os quais os alunos assimilam ativamente conhecimentos, habilidades, atitudes e convicções. No entanto, a formação profissional do professor é um processo pedagógico, intencional e organizado, de preparação teórico-científica e técnica para dirigir competentemente o processo de ensino. De qualquer forma, a participação dos professores depende de sua formação profissional e interesse pela temática ambiental, sendo um constante desafio sua atualização pedagógica e científica.

A dinâmica da escola, as características de formação e as condições de trabal ho do professor, bem como a falta de material pedagógico para abordar a temática da Educação Ambiental, são fatores que podem dificultar a concretização de atividades de Educação Ambiental. Segundo SANTOS, (1998), os professores necessitam de literatura apropriada ao tema, material didático e grupos de apoio capazes de auxiliarem no planejamento ou na execução de idéias.

Portanto, o trabalho de Educação Ambiental no ensino fundamental e médio deve contar com a participação dos professores, sendo ele o mediador entre 0 aluno e 0 objeto de seu conhecimento e, dessa forma, responsável por despertar a curiosidade por meio de ações pedagógicas definidas. N esse sentido, trabalho conjunto com professores no sentido de elaborar propostas de E ducação Ambiental em áreas urbanas, a partir de oficinas pedagógicas, parece ser uma alternativa para a formação de uma consciência ecológica ativa, crítica e próxima à realidade de alunos e professores.

\section{Praça pública: lazer, memória cultural e ensino}

Praças e jardins públicos caracterizam-se por possuir, na maioria das vezes, espaços e áreas verdes que ajudam a manter o clima ameno nas áreas urbanas, sendo capazes de dar condições de sobrevivência a um vasto número de espécies da fauna e flora ali presentes. Esses locais apresentam uma vegetação, nativa ou exótica, localizada na área urbana e, portanto, fazendo parte dela. Estima-se também o valor paisagístico e cultural do local, onde fatos históricos e sociais permearam sua existência. É nesse sentido que tais locais são um componente importante no ecossistema urbano, uma vez que dispõe de um espaço natural dentro do ambiente construído pelo homem.

Ainda, tais locais podem conter informações sobre a diversidade cultural e social dos freqüentadores, trazendo enriquecimento e valorização da cultura local. CARvalHo (1998) considera que a cultura deve ser sempre vista como um meio de interação entre os indivíduos e os grupos sociais, possibilitando um hibridismo de costumes, culturas e etnias, produzindo uma diversidade cultural. Portanto, esse encontro de culturas étão importante quanto a diversidade biológica, mas pode ser prejudicado pela ausência de planejamento durante o desenvolvimento das cidades (CAM IN HAS, 1992).

\section{Relevância histórica do município}

0 município de Botucatu foi fundado em 1855. A cidade desenvolveu-se graças aos ciclos econômicos que permearam o final do século XIX e início do século XX. D essa maneira, a produção de couro e o cultivo e beneficiamento de café trouxeram fazendeiros, trabal hadores rurais e dinheiro à cidade. Em meio a seu desenvolvimento, ao final do século XIX, a 
cidade passou por projeto de reurbanização. Avenidas largas, cal çamento de paralelepípedo e terrenos transformados em quarteirões representavam a recém instalada República. A cidade, com isso, organizou-se, passando a ter condições de entrar no século XX preparada para 0 desenvolvimento iniciado no interior do Estado de São Paulo.

0 resultado dessa reorganização da cidade possibilitou a construção de áreas verdes com estilo europeu e, entre elas, encontra-se a Praça Rubião Júnior. Inaugurada em 1916, com plantas de várias partes do mundo e um estilo arquitetônico característico da época, tornouse centro de atividade política e social e serviu de ponto de encontro da população nessa área verde dentro do centro urbano.

Atualmente os prédios ao redor da Catedral M etropolitana (localizada em frente à praça) são tombados pelo Patrimônio H istórico; no entanto, o crescimento da população, aliado a estratégias equivocadas de planejamento urbano, podem trazer conseqüências para a preservação do centro histórico. Assim, somente a conscientização da população sobre a riqueza histórica e ecológica desse ambiente urbano poderá estabelecer metas de preservação de suas características arquitetônicas e biológicas.

o local escolhido como referência para o trabalho com professores e alunos foi a Praça Rubião Júnior. Esse espaço, considerado como patrimônio histórico da cidade de Botucatu-SP, permite relatar algumas páginas da sua história, uma vez que foi o centro da urbanização e crescimento dessa cidade. Para transformar esse local num espaço apropriado às atividades educativas, foi necessário buscar e sistematizar os aspectos sociais, econômicos, políticos, culturais e botânicos, que podem ser utilizados na abordagem interdisciplinar da Educação Ambiental, visando a uma mudança no comportamento e nas concepções de seus visitantes. Com tais informações pode ser possível trabalhar com os professores em oficinas e atividades pedagógicas que contemplem os objetivos das diferentes disciplinas, possibilitando 0 desenvolvimento de um programa de Educação Ambiental em áreas urbanas.

\section{0 ficinas pedagógicas a partir dos princípios da pesquisa ação-participativa}

Este trabalho foi desenvolvido segundo alguns princípios da pesquisa participativa, em que temas préselecionados foram colocados em discussão com os professores. Tal metodologia possibilita a permanente construção coletiva em que os envolvidos tornam-se investigadores, conduzindo o conteúdo e as propostas metodológicas. Esse tipo de pesquisa possui base empírica, que é concebida e realizada com a aproximação da ação com a resolução de uma problemática coletiva na qual os participantes cooperam e participam da construção do objeto pedagógico.

\section{a) Pesquisa histórica}

Foi feita uma ampla pesquisa sobre a história do município de Botucatu-SP, por meio de entrevistas com escritores contemporâneos, assim como revisão nos jornais e livros do Centro Cultural da cidade. A elaboração de material utilizado nas oficinas com os professores buscou relacionar os conteúdos de história, biologia, geografia e ciências.

A primeira fonte para o levantamento da histórica foi a Internet, por meio do website da cidade de Botucatu (http://www. guiadebotucatu.com.br), o qual contém informações sobre a história e o desenvolvimento da cidade. Após análise desse material, foram enumerados os principais fatos relacionados com a história de Botucatu, seus protagonistas e principalmente os assuntos relativos à Praça Rubião Junior.

0 arquivo de fotos foi composto por cópias gentilmente cedidas por colecionadores, armazenadas em CD -Rom, das quais se fez uma coleção de sides. Ao final foi elaborada uma apresentação com os principais fatos sobre a história do município. 
Foram também abordados aspectos relacionados com a origem, a ecologia e a importância para o homem de cada uma das plantas existentes na praça em estudo de acordo com JANKE (2002). Assim, foi feito um levantamento das possibilidades de temas relacionados com o conteúdo do ensino fundamental e médio de modo a aproximar os temas de sala de aula com os que as plantas da praça oferecem.

\section{b) Seleção e contato com as escolas}

Após a produção do material para a oficina, foi iniciado o contato com as escolas que se localizam próximo à praça. As escolas que foram convidadas a participar da oficina foram: Escola Estadual Dr. Cardoso de Almeida (ensino fundamental e médio), Colégio Santa M arcelina e Colégio La Salle. 0 material entregue aos coordenadores consistiu em uma carta de apresentação, um cronograma da oficina, além do material histórico e botânico resumidos.

Depois do contato com as coordenadoras pedagógicas das escolas que, a priori, deveriam participar da oficina, a única escola que se organizou a tempo para a realização da oficina foi o C olégio La Salle de Botucatu. As outras contatadas demonstraram interesse e disposição, porém se organizaram tardiamente, impedindo 0 agendamento das oficinas para os meses de setembro a outubro.

A oficina foi organizada em seis módulos, havendo um encontro a cada semana com duração média de duas horas. Em seguida, foram realizadas atividades com os alunos das séries escolhidas pelos professores, sendo mais um módulo utilizado para a aplicação da proposta de Educação Ambiental e para a avaliação dos alunos, dos professores e da própria oficina ALm EIDA et al., 2003, no prelo). Por fim se elaborou um cronograma para o desenvolvimento da oficina, contendo os objetivos desta, o conteúdo e o cronograma das atividades a serem realizadas.

\section{c) Coleta de dados para a oficina}

Todos os encontros da oficina foram realizados no Colégio La Salle e registrados em gravações feitas em fita cassete, sendo elaborado um relato dos assuntos discutidos nos seis módulos da oficina.

Foram discutidos os assuntos relacionados à história de Botucatu e a praça, as atividades que os al unos poderiam executar na praça, bem como as plantas selecionadas para serem "observadas" pelos alunos. Todas essas atividades foram pensadas e refletidas pelos professores durante os encontros na oficina.

D a mesma maneira, foi planejado o número e 0 teor das atividades relacionadas às séries específicas, previamente selecionadas pelos professores para a aplicação da proposta. Procurou-se levar em consideração as perspectivas dos professores e seus conhecimentos teóricos e práticos sobre o processo pedagógico, além de seus conhecimentos sobre as competências e habilidades dos alunos das séries envolvidas.

A apresentação de slides, bem como a aula sobre história e o levantamento florístico, foram sendo apresentados em seqüência durante os encontros, possibilitando aproveitar e produzir um maior número de sugestões e propostas. Assim as discussões tiveram um caráter seqüencial, em que os pontos relevantes foram apresentados conforme o contato e o conhecimento do material levado à oficina.

$\mathrm{N}$ a medida em que as impressões dos professores foram sendo registradas, a construção da proposta foi realizada continuamente durante os encontros na oficina. D essa maneira, foi produzida a proposta de Educação Ambiental levando-se em con- 
sideração os aspectos importantes, na visão dos professores, para serem aplicados na aula.

Assim, a proposta final do Programa de Educação Ambiental na Praça foi elaborada a partir do conteúdo dos encontros com os professores, produzindo um material que possibilita a utilização pelos mesmos nas diferentes disciplinas que atuam.

\section{d) 0 s encontros na oficina}

Os encontros na oficina foram registrados e, posteriormente, discutidos entre os professores, de modo a permitir uma elaboração da proposta de Educação Ambiental para a Praça Rubião Junior. Aspectos significativos do material elaborado, bem como a própria partici pação dos professores, foram os instrumentos para elaborar, executar e avaliar tanto a oficina com os docentes como a proposta de Educação Ambiental aplicada em duas séries do ensino fundamental (4a e 6a séries).

No primeiro módulo foi feita a apresentação dos participantes, bem como do cronograma proposto. A oficina teve inicialmente cinco professores inscritos e que estiveram presentes nesse primeiro encontro, sendo três de História e Geografia e dois de Ciências e Biologia. Após as apresentações, foi exposto 0 objetivo da oficina, bem como a importância da participação efetiva de todos os professores nela. Enfatizou-se a importância do conhecimento da história local como instrumento importante para a realização de uma proposta de Educação Ambiental na praça Rubião Junior em Botucatu.

$\mathrm{N}$ esse encontro, as fotos antigas da cidade, preparadas sob a forma de slides, foram importantes para a explanação da história de Botucatu. Essa combinação de recursos áudio visuais e explanação oral foi comentada pelos professores como sendo de grande importância para esse tipo de abordagem. Além disso, os diapositivos compõem um recurso que chama a atenção dos alunos e propicia uma relação mais próxima com o conhecimento histórico. Alguns professores não sabiam onde se localizava a praça em questão, porém outros já tinham conhecimento sobre alguns fatos históricos da cidade. Isso proporcionou, além do prévio conhecimento do local, uma discussão entre eles, evidenciando o potencial dos fatos sócio-político-culturais da história da cidade.

No segundo módulo foram apresentados os materiais resultantes da pesquisa histórica: cópias de exemplares dos jornais antigos e um conjunto de fotos antigas e recentes. Por ser uma atividade que envolvia ver e manusear determinado material, os professores interagiram entre si, possibilitando um maior número de sugestões e discussão sobre o material. D a mesma maneira, todo o material foi acompanhado de informações e contextualizações históricas previamente preparadas como parte da atividade.

A riqueza que os registros históricos desse material propicia para a prática educativa foi 0 aspecto mais relevante levantado pelos professores nesse encontro. Para tanto, demonstrou-se a preocupação destes em colocar esse material à disposição dos alunos de modo a estimular o interesse sobre as questões históricas. Além disso, uma relação entre a história e a conservação do meio ambiente pode ser especificada quando da utilização de notícias referentes ao crescimento da cidade e de suas atividades econômicas, em especial, aos aspectos que envolvem a agropecuária da região.

0 terceiro módulo consistiu em levar os professores para percorrerem a "triIha" pré-elaborada na praça Rubião Junior. Foram selecionados, de JAN KE (2002), 13 
pontos e 12 plantas para serem abordadas com os participantes, buscando-se aproximar as informações biológicas e históricas aos conteúdos curriculares. Também se procurou relações entre tais informações e o cotidiano do aluno por meio de discussões sobre 0 uso de plantas para medicamento, bem como exemplos de plantas que servem de matéria-prima para alguns produtos industrializados de uso do homem.

No quarto módulo foram discutidos todos os elementos e sugestões apresentadas pelos professores. Percebeu-se que a história da cidade e a praça oferecem inúmeras possibilidades para os trabalhos de Educação Ambiental, desde que planejados.

Segundo os professores, na 4a série poderia ser trabalhado o tema "Classificação e i dentifi cação das partes vegetais", bem como uma breve explanação sobre a história local, que possibilitasse o reconhecimento de fotos urbanas com as paisagens antigas e atuais. $\mathrm{N}$ a 6a série, segundo os professores, a mesma abordagem histórica motivaria e despertaria 0 interesse dos alunos; todavia, a visita na praça precisaria ser adaptada ao desenvolvimento cognitivo dos estudantes das diferentes séries.

0 quinto módulo teve 0 intuito de preparar e organizar as atividades a serem realizadas com os alunos na proposta de Educação Ambiental, fazendo um apanhado geral de tudo que já tinha sido discutido. Além disso, novas sugestões apareceram e foram discutidas e incorporadas na proposta em construção.

O s professores comentaram sobre a possível reação e o interesse dos al unos para alguns fatos históricos ou informações botânicas. D essa maneira, para os docentes, os slides seriam o melhor recurso para a apresentação das fotos, pois permitem a comparação de fotos antigas com locais atuais e melhoram a qualidade da aula.

Trabal hando dessa forma, os professores passam a ter um papel importante na elaboração e execução de propostas de Educação Ambiental (KRASILCHIK, 1986), uma vez que colocam suas expectativas e seus conhecimentos sobre e para a prática educativa. $\mathrm{N}$ as oficinas realizadas, os professores, embora de diferentes disciplinas, foram capazes de elaborar uma proposta de Educação Ambiental, em que pôde ser exigido conhecimento das demais disciplinas curricular e, dessa maneira, segundo Seara FILHo (1992), abordar a questão ambiental a partir do trabalho conjunto com várias disciplinas, num enfoque interdisciplinar que intencionalmente procure as relações e os vínculos existentes nas várias disciplinas, parece proporcionar um entrelaçamento entre indivíduo e sociedade, conhecendo a pluralidade do mundo.

0 sexto módulo sistematizou as atividades, chegando na Proposta de Educação Ambiental para a Praça Pública Rubião Junior, em Botucatu-SP. A proposta de Educação Ambiental elaborada pelos professores apresentou caráter interdisciplinar, uma vez que, além de envolver docentes da diferentes disciplinas, as atividades exigem dos alunos conhecimentos e relações entre arte, música, geografia, ciências e história, conforme mostra 0 Q uadro 1. 


\begin{tabular}{|c|c|}
\hline . para & roposta de E. A. para a 6ạ série \\
\hline $\begin{array}{l}\text { Aula expositiva } \\
\text { - Apresentação da história de Botucatu, } \\
\text { com } 13 \text { slides e comentários sobre os aspec- } \\
\text { tos que levaram ao desenvolvimento de } \\
\text { Botucatu. } \\
\text { - Trilha na praça com a utilização de três } \\
\text { plantas pré-selecionadas (Ficus auriculata, } \\
\text { Ficus sp, Gallesia integrifolia, e seus respecti- } \\
\text { vos nomes populares, figueira-da-Índia, } \\
\text { mata-pau, pau d'alho). } \\
\text { - D esenvolvimento de conteúdos relaciona- } \\
\text { dos a essas plantas. } \\
\text { Atividades em grupo } \\
\text { - O bservar e desenhar a menor e a maior } \\
\text { folha dos vegetais presentes na praça. } \\
\text { - O bservar e contar quantas árvores esta- } \\
\text { vam com flores. } \\
\text { - O bservar e localizar quantas árvores de } \\
\text { Ficusauriculata foram plantadas pelo arqui- } \\
\text { teto da praça. } \\
\text { - O bservar, localizar e desenhar as constru- } \\
\text { ções antigas que ainda restam ao redor da } \\
\text { praça. } \\
\text { - I dentificação dos sons, da natureza e urba- } \\
\text { nos, que envolvem a praça. } \\
\text { - D esenho livre que explicitasse os sons e a } \\
\text { praça em si, numa cartolina com giz de } \\
\text { cera. }\end{array}$ & $\begin{array}{l}\text { Aula expositiva } \\
\text { - Apresentação da história de Botucatu, } \\
\text { com } 13 \text { sides e comentários sobre os aspec- } \\
\text { tos que levaram ao desenvolvimento de } \\
\text { Botucatu. } \\
\text { - Trilha na praça com a utilização de três } \\
\text { plantas pré- selecionadas (Ficus auriculata, } \\
\text { Ficus sp, Gallesia integrifolia, e seus respecti- } \\
\text { vos nomes populares, figueira-da-Îndia, } \\
\text { mata-pau, pau d'alho). } \\
\text { - D esenvolvimento de conteúdos relaciona- } \\
\text { dos a essas plantas. } \\
\text { Atividades em grupo } \\
\text { - Localizar três diferentes plantas e dese- } \\
\text { nhar suas folhas no caderno. } \\
\text { - Escolher uma folha desses vegetais e dese- } \\
\text { nhá-la num papel de seda, procurando } \\
\text { visualizar os contornos das nervuras e o for- } \\
\text { mato da folha. } \\
\text { - O bservar e quantificar o número de árvo- } \\
\text { res com flores. } \\
\text { - O bservar, localizar e desenhar as constru- } \\
\text { ções antigas que ainda restam ao redor da } \\
\text { praça. } \\
\text { - Compor uma letra de música que tenha as } \\
\text { seguintes palavras: natureza, história, pre- } \\
\text { servação, respeito, futuro, saúde, árvores, } \\
\text { folhas, flores e pássaros. }\end{array}$ \\
\hline
\end{tabular}

\section{Q uadro 1 - Proposta de Educação Ambiental, de 4ạ e 6a séries elaborada pelos professores durante os encontros na oficina}

\section{A oficina como instrumento de construção coletiva: resultados obtidos}

A Proposta de Educação Ambiental construída pelos professores foi pensada em dois momentos a serem trabalhados com os alunos:

1) $\mathrm{N}$ as dependências da escola, com uma explanação oral ilustrada com sides, apresentando a história de Botucatu.

2) Na praça, percorrendo a "trilha" (com plantas selecionadas pelos professores) e também com a execução de atividades lúdicas com os alunos.

Para a aula sobre a história de Botucatu (1), os professores participantes da oficina destacaram os seguintes objetivos pedagógicos a serem explorados: 
- Adequar a linguagem histórica, abordando os fatos mais relevantes que tenham

ligação com a cidade de Botucatu.

- Relacionar esses fatos com o desenvolvimento da cidade.

- M ostrar a falta de preservação da cultura local.

Fazendo um paralelo com o que afirma VEIGA (1993), a aula expositiva é importante, pois se torna executável em qualquer nível de ensino. Em Educação Ambiental, aulas que preparem ou criem uma expectativa no aluno podem ser uma eficiente estratégia para um melhor aproveitamento da proposta. N esse sentido, a exposição oral pode trazer resultados bastante significativos na aprendizagem e incorporação de informações.

Para a visita na praça (2) foram selecionados, pelos professores, al guns itens com 0 objetivo de desenvolver competências e habilidades referentes às séries envolvidas. D essa maneira, foram destacados os seguintes pontos:

- Utilização das casas antigas como exemplo da arquitetura do início do século.

- Elaboração de atividades que desenvolvam algumas habilidades nos alunos.

- Estimulação do reconhecimento e identificação das plantas presentes na praça.

RoBIM e TABANEZ (1993) constataram que, quando uma trilha interpretativa é composta por uma preparação prévia e seguida da execução da trilha propriamente dita, 0 resultado parece possibilitar um maior interesse por parte dos alunos. Assim, o uso das informações das plantas, associadas ao cotidiano do aluno, durante a trilha, pode ser uma eficiente estratégia de envolver os alunos com as questões ambientais.

As atividades em grupo sugeridas pelos professores consistem em estimular as habilidades dos alunos e proporcionar uma discussão entre eles, o que pode enriquecer o processo educativo. Segundo N oт (1993), o trabalho em equipe habitua os participantes à cooperação com discussão e planificação de atividades, possibilitando a repartição de tarefas visando a uma eficácia melhor desse processo.

D equalquer maneira, as atividades em grupo planejadas pelos professores para a proposta de Educação Ambiental consistiram em estimular a observação dos alunos para dentro da praça e seus arredores e para a problemática da falta de preservação da cultura, da história e do próprio patrimônio histórico. N essas atividades também se procurou estabelecer uma relação de respeito com a natureza por meio da ênfase de sua importância para o homem e toda a sociedade moderna.

D esenvolver a curiosidade dos alunos, segundo os professores, necessita de atividades quetornem 0 aluno ativo durante a prática, possibilitando a ele descobrir e construir o conhecimento. Assim saber "o que" a praça possui, "como" está sua conservação e "onde" se localiza no contexto urbano e his tórico parece trazer benefícios para um mehor aproveitamento de atividades de Educação Ambiental.

\section{Ambiente urbano como espaço educativo: uma reflexão para os professores}

A prática da Educação Ambiental enriquece o processo educativo e traz instrumentos para os professores trabal harem em diferentes conteúdos articulados entre si. Da mesma maneira, a participação desses docentes na elaboração de propostas de Educação Ambiental favorece sua formação e sua reflexão dentro da prática educativa. $\mathrm{N}$ a proposta de $\mathrm{E}$. $\mathrm{A}$. deste trabal ho, os professores atuaram planejando e organizando as atividades, além de avaliarem 0 trabal ho na oficina e a proposta construída por eles.

A abordagem histórica foi considerada ideal pelos professores, pois possibilitou elaborar uma parte da proposta de Educação Ambiental. Ainda, uma professora - de geografia - reafirmou a necessidade de se colocar em CD-ROM uma sequêencia de fotos e a própria história de Botucatu, concordando com outros professores que esse é um material que possibilita o trabal ho deles em qualquer momento da matéria de história e geografia, desde que esteja pronto e coerente com as necessidades dos professores. 
Em relação às atividades lúdicas, o desenho na cartolina com o giz de cera para a 4a série foi considerado pelos professores a atividade que melhor demonstrou o desempenho dos alunos. U ma professora - de geografia - comentou: "muitas crianças nunca tinham ido à praça, mas, na hora de passar para o papel, souberam desenhar o laguinho, o banheiro, o Ficus, enfim, colocaram tudo. É sinal de que eles observaram". Essa atividade destaca a importância da observação e possibilita a organização e o registro de informações para essa série, trazendo um aprendizado significativo, uma vez que trabalha com a análise e síntese de informações.

A atividade de composição musical executada pela 6a série foi considera ótima pelos professores, sendo que estimulou a criatividade dos alunos. No entanto, os docentes comentaram a necessidade de se organizar melhor a atividade, pois, na execução, a voz dos alunos não se sobressaia dos outros sons urbanos da praça. D e qualquer maneira, essa atividade é viável, desde que se prepare os alunos e o material utilizado de forma adequada.

O s professores comentaram também a necessidade da preparação começar pelos próprios docentes. A professora de geografia comentou: "muitos professores não estão bem orientados para trabalhar na praça. Agora, a partir dessa oficina, nós temos condições de usar a praça como espaço de sala de aula". G o N ÇALVES (1988) destaca a necessidade dos professores de se prepararem para a prática no local que desconhecem, buscando evitar problemas com os alunos. N essa perspectiva, a realização de oficinas para a elaboração e execução de uma proposta de Educação Ambiental pode ser um caminho para a preparação e adequação de professores para a prática da Educação Ambiental .

O s docentes falaram ainda sobre a necessidade de sempre se estar refletindo sobre as práticas educativas, no sentido de aprimorar as aulas e desenvolver mais habilidades nos alunos. A avaliação constante de professores e alunos pode contribuir para a construção de programa permanente de Educação Ambiental na Praça Rubião Junior. N esse contexto, LIBÂN EO (1994) comenta quea avaliação éum procedimento didático que permite acompanhar detalhadamente o processo de ensino eaprendizagem, além de ter um caráter permanente durante a prática educativa. Tanto professores quanto alunos são comparados aos objetivos propostos de forma a permitir uma reflexão da prática a fim de detectar progressos, dificuldades e reorientar o trabal ho para as correções necessárias.

A aproximação da universidade com a escola foi um fator importante citado pelos professores. A professora de geografia julga a oficina como um trabalho de grande aprendizado e essencial para um acréscimo a sua experiência. De modo geral, ela sintetiza dizendo: "é um trabalho envolvendo nossa cidade, de interesse de todos, tanto professores, quanto alunos".

Por fim, o material preparado para a oficina, foi visto pelos professores como uma "possibilidade de inter-relação entre as disciplinas de história, geografia, biologia, matemática, educação artística, português, formando um conjunto harmonioso de assuntos". Tal concepção é coerente com a proposta de CARVALH O (1992); a Educação Ambiental pode ser desenvolvida como um processo educativo com o conjunto e 0 andamento de todas as disciplinas, mostrando que a Educação Ambiental é uma tarefa multidisciplinar e requer um enfoque interdisciplinar.

Tal metodologia de trabalho articula-se com o que KRASILCHIK (1987) chama de curso analítico-paticipativo, em que há um trabalho coletivo de produção e discussão que resulta na elaboração de materiais e no desenvolvimento de novas técnicas que valorizam o processo de transformação e evolução do profissional. WEID (1997) diz que a estratégia de conhecer os problemas da sociedade local é um ótimo caminho para a escola; professores e alunos contribuem para a produção e divulgação dos conhecimentos sobre as realidades sócio-ambientais do local em estudo. O ficinas com professores parecem ser uma maneira de formar profissionais ou capacitálos para uma prática educativa renovada, buscando-se a recuperação dos valores sociais, culturais e ambientais.

D essa maneira, a avaliação da oficina esua aplicação, além de detectar a apreensão dos valores, deve possibilitar uma reflexão sobre o comportamento dos educandos, sendo uma possibilidade 
permanente, nas atividades deEducação Ambiental, propiciando analisálas e replanejálas. Assim, as trilhas interpretativas, bem como toda a atividade de Educação Ambiental, são meios de interpreta ção ambiental que não se resumem somente à transmissão de conteúdo, mas devem envolver a análise dos significados e característica do próprio ambiente (TABANEZ et al., 1997).

\section{Considerações finais}

A abordagem histórica do local propõe a promoção do auto-conhecimento e 0 conhecimento do Universo por meio do resgate de valores e da reconstrução de referências espaciais e temporais que possibilitem uma mudança de valores fundamentados na diversidade cultural e na visão global e holística do mundo, buscando a ação local. Essa definição também foi proposta por SORRENTINo (1998), que a identifica como um dos temas e objetivos dos projetos de Educação Ambiental, de "espi ritual-culturais", em que o conhecimento de refe rências históricas pode reconstruir valores baseados numa nova visão global do mundo.

D essa maneira, o objeto de trabalho na Educação Ambiental é o ser humano, a sociedade como um todo, em que a percepção do local precisa considerar o universal no particular, resgatando história, relações, processos que sustentam e justificam a própria existência daquele local. A E. A. urbana, portanto, pode ser executada na cidade, bairro ou periferia, além de ser viável em praças públicas, como extensão da sala de aula. Portanto, na interdisciplinarização da história, a relação ambiental está sendo resgatada, fundamentando sua importância no debate sobre aquele meio (CASCIN O, 1998) em atividades de E. A. em áreas urbanas.

Assim, oficinas pedagógicas que envolvam professores na temática urbana podem ser uma alternativa para a prática pedagógica da Educação Ambiental. Essas atividades levam a uma reflexão sobre as relações históricas e sociais existentes no local e promovem um trabal ho conjunto de professores e alunos, em que há uma construção coletiva e reflexiva das práticas nelas elaboradas e executadas. Assim, a consciência ecológica foi estimulada, bem como a ação desses alunos, como cidadãos que se preocupam com o futuro da cidade. N esse sentido, essa proposta pode, e deve, ser repensada nas escolas, procurando seguir algumas das indicações dos alunos e dos professores do Colégio La Salle do ensino fundamental. Atividades envolvendo representação artística, como teatro, com um maior número de materiais de livre manuseio, com elementos para construção de maquetes e informações, podem ser testadas nessa proposta de Educação Ambiental.

D e qualquer forma, a observação e interação dos alunos com 0 ambiente social e 0 ambiente natural podem estar sendo estimuladas a partir de oficinas nas quais seus professores podem construir ativamente as atividades pedagógicas. De acordo com o interesse de seus alunos, atividades de Educação Ambiental em praças públicas podem estimular o "olhar para dentro" e o "olhar para fora" do local escolhido para as atividades, levando à compreensão do ambiente urbano e ao entendimento de suas relações com a natureza.

\section{Agradecimentos}

À diretoria e aos professores do Colégio La Salle de Botucatu-SP.

À Srâ N adja Janke, aluna do programa de pós-graduação em Educação para a Ciência da U N ESP, C ampus de Bauru, pela leitura e sugestões apresentadas.

A PRO EX, pelo incentivo financeiro cedido ao projeto "Educação Ambiental em Praças Públicas no município de Botucatu-SP".

\section{Referências}

AB'saber, A. N . (Re)conceituando educação ambiental. São Paulo: CN Pq/M ast, 1991. 
ALm EIDA, L. F. R.; BICUdo, L. R.; Borges, G. L. A. Educação ambiental em praças públicas: professores e alunos descobrindo o ambiente urbano. Ciência e Extensão, v. 1, 2004 (no prelo). C AM IN H AS, A. M. T. Excursão no conhecimento do ambiente: uma associação entre os aspectos históricos e biológicos. Botucatu, 1992. Trabalho de Conclusão de Curso (Licenciatura em Ciências Biológicas) - Instituto de Biociências, UN ESP.

Carvalho, I. C. M. Educação, meio ambiente e cidadania. In: Congresso SOBRE EsSÊn CIAS N ATIVAS, 2, 1992, São Paulo. Anais... São Paulo: Instituto Florestal, 1992, p. 1081-5. Carvalho, L. M . Os trabalhos de campo como procedimento didático. In: São Paulo (Estado). Secretaria de M eio Ambiente. Coordenadoria de Educação Ambiental. A qualidade das águas. São Paulo: SM A/CEAM , 43 p., 1998.

CASCIN O, F. Educação ambiental: exxos teóricos para uma reflexão curricular. In: ; JACOBI, P.; O LIVEIRA, J. F. (org.). Educação, meio ambientee didadania. São Paulo: SM A - CEAM , 120 p., 1998. Gon Çalves, M. L. Q. A importância das excursões no ensino de biologia. In: São Paulo. Secretaria da Educação. Coordenadoria de Estudos e N ormas Pedagógicas. Ensino de bi ologia: dos fundamentos à prática. São Paulo: SE/CEN P, 1988. v. 1, p. 35-42.

JACOBI, P. Educação ambiental e cidadania. In: CASCINO, F.; JACOBI, P.; O LIVEIRA, J. F. (org.). Educação, meio ambiente e cidadania. São Paulo: SM A - CEAM, 120 p., 1998.

JAN KE, N .; BICUDO, L. R. H . A vegetação da Praça Rubião Júni or, município de Botucatu-SP, como instrumento para atividades de Educação Ambiental. Botucatu, 2002. $61 \mathrm{f}$. Trabalho de Conclusão de Curso (Licenciatura em Ciências Biológicas) - Instituto de Biociências, UN ESP. KRASILCHIK, M. Educação ambiental no currículo escolar. In: SIM Pó SIO DE

Educação Am biental, 2, 1987, Santos. Anais... Santos: M useu de Pesca, 1987, p. 39-45. . Educação ambiental na escola brasileira - passado, presente e futuro. Ciência e Tecnologia, v. 38, n. 12, p. 1958-61, 1986.

LibÂN EO, J. C. Didática. São Paulo: Cortez, 1994. (M agistério 20 grau, 260)

N OT, L. Ensinando a aprender: elementos da psicodidática geral. São Paulo: Summus, 1993. Reig OtA, M. M eio ambiente e representação social. São Paulo: Cortez, 1995. 87p.

Ro BIM , M. J.; TABAN EZ, M. F. Subśdios para implantação da Trilha Interpretati va da Cachoei ra - Parque Estadual de Campos de Jordão. Boletim Técnico, v. 5, n. 1, p. 68-89, 1993.

SANTOS, A. A. N. Proposta de um programa de Educação Ambiental para alunos do Ensino Fundamental no Jardim Botânico da U N ESP/Botucatu, 1998. Dissertação (M estrado em Ciências Biológicas) - Instituto de Biociências, UN ESP.

SeARA Filho, G. Educação Ambiental: questões metodológicas. Ambiente, v. 6, p.1, p. 45-48, 1992.

So Rrentino, M. DeT bilisi aT hessaloniki. A Educação Ambiental no Brasil. In: CASCIN O, F.; JACOBI, P.; O LIVEIRA, J. F. (org.). Educação, méo ambientee didadania. São Paulo: SM A - CEAM , 120 p., 1998. TABAN EZ, M . F. et al. Avaliação de trilhas interpretativas para educação ambiental. In: PÁduA, S. M ., TABAnez, M. F. (org.) Educação ambiental, caminhos trilhadosno Braśl. Braślia: IPÊ, 1997. 283 p. VEIG A, I. P. A. (coord.) Técnicas de ensino: por que não? C ampinas: Papirus, 1993. WEID, N . V. D . A formação de professores em Educação Ambiental à luz da Agenda 21. In: PÁduA, S. M .; T ABAn Ez, M . F. (org.). Educação Ambiental, caminhos trilhados no Brasil. Braślia: IPÊ, 283 p. 1997.

\section{Artigo recebido em julho de 2002 e selecionado para publicação em outubro de 2003.}

